\title{
DECONSTRUCTION OF THE PLANNING PROCESS IN THE 21ST CENTURY
}

\begin{abstract}
By increasing the changes in the last years of the second millennium, relying on the planning methods, which are based on forecasting, cannot meet the needs of management of countries at large scale. The heavy burden of uncertainties and emergence of interrupted and wild card events have changed the conditions in a way that future forecasting is not possible for planners. On the other hand, in regional and urban planning it is necessary to change the attitude from forecasting to foresight. Considering this, the paper attempts to introduce the approach of foresight as well as having a critical view of the current process of planning in foreseeing and future studies. Moreover, this study emphasizes the necessity of employing the foresight approach in the process of urban and regional studies.
\end{abstract}

Key words: foresight, planning process, processes re-engineering.

\section{INTRODUCTION}

Current world is the field of wonderful transitions with increasing dynamics. The changes emerge so surprising that even a little neglect may result in the costly strategic negligence in fields such as politics, economics, sociology, and even culture. Future formation is the approach and policy that is likely to obtain more success in this environment where plenty of alterations, instabilities and uncertainties are present. Although the effort has always been accompanied by taking high risks, it is more advisable to take such risks instead of just observing future changes (Khazaee, 2007).

Other than paying serious attention to current challenges and offering strategies, mission and planning in developed countries is nowadays devoted to considering future challenges and methods for encountering them and gaining power in such

\footnotetext{
* Nader ZALI, Department of Urban Planning, Faculty of Art and Architecture, University of Guilan, K6 Tehran-Rasht Road, P.O. Box 1841, Rasht, Iran, e-mail: N.zali54@gmail.com
} 
scopes. Promoting its role, planning now attempts to conquer future, play a significant role and partake in future.

Due to intrinsic desire, man has always been fond of discovering the future and decoding it. Questions such as 'how is future predictable?', 'will future be the continuation of present and past?', 'what events are likely to happen in future?' (Schwartz, 2008) and so on, have been so far the main mental challenges for planners and managers. The planners have therefore taken various approaches for encountering future problems chiefly based on analyzing previous procedures and extending them to future. However, in order to achieve comprehensiveness in planning in the beginning of third millennium, future study has unified the diffused field of planning for future and has converted it into an organized science whose function is to discover, invent, and evaluate the possible, probable and preferable futures, together with analyzing previous procedures (Myer, Kitsuse, 2000).

\section{STATEMENT OF THE PROBLEM}

In current changing conditions, some issues in development planning, such as information technology and its development, promotion of hygienic and educational indexes, forming infrastructure networks and improving social services, should not be considered as potential scopes for future development, rather as the prerequisites and preliminaries of development in future world. The actual development in future world originates from progress in fields such as space contest, artificial intelligence, genetic engineering, the wonderful virtual world and so on, whereas this superb world will occur in less than three decades, as most researchers in future study believe. Indeed, planning for future based upon present requirements or current service insufficiencies would not be an appropriate national capital for being successful in future world. For playing a major role in future, it is therefore necessary to rely on latest planning approaches and make scenarios for development and future alterations based on megatrends and discrete procedures, while analyzing present and future challenges and planning to be successful in future in accordance with society potentials and capabilities. In other words, modern planning has passed concepts such as prediction and discovering future, and has reached the scopes of future study and foresight whose duty is to map future and form it.

In fact, existing problems in human society originate from two main factors; the former is not to gain a smart realization of future in past time episodes, while the latter pertains to marvellous changes in technologies together with globalization. As a result, it is considered necessary and a major priority to identify future alterations with a foresight approach. 
Great deals of future events are predictable and can be subjugated, so it is possible to make favourable changes. In most cases, however, being engaged in present time and trying to solve existing problems prevents managers and decision-makers from contemplating future. It is noteworthy that alongside active participation in the process of future transitions, decreasing threats and increasing opportunities and choices require a future study approach which facilitates to show an active performance in future events (Khazaee, 2007).

Not gaining a smart realization of future in past time episodes is caused by planning tools and how they are utilized in process of planning (Myer, Kitsuse, 2000). These tools and techniques are indeed the executive cover of planning process and in some cases, either an incorrect selection of executive covers or a wrong choice of planning process itself due to following the routine steps causes numerous problems in the society under planning. So far, in evaluating these cases, the fundamental problems in planning process framework have not been mentioned and governors together with executors of plans have been known to be responsible for the resultant undesirable society. Nevertheless, the main responsibility for programmes to be successful or unsuccessful is better to be attributed to planners, especially the ones dealing with future study of the programs.

Based upon these facts, it is nowadays necessary to apply reengineering to planning process and change the fundamental theory of planning steps. Furthermore, recent conditions of world society, the influence of scientific and technological transitions on creating new problems, and solving a great deal of problems in present society have made it inevitable to consider the topic of changing the planning frameworks.

In the 1970s, the science and art of foresight was officially used as a tool for making policy in a limited number of countries, especially Japan. This method, however, was employed extensively in the 1990s with collaboration of international institutions in order to empower the countries, and it has become the dominant approach of planning in most developed countries (Nazemi-Ghadiri, 2006).

\section{ANALYSIS OF MACRO APPROACHES IN PLANNING}

Planning is man's tendency towards future, solving future problems, forecasting and hope in future (Faludi, 1970). In the scope of planning for future, two major paradigms exist, namely exploratory and normative paradigms, each of them having its specific viewpoint to the concept of future and how to reach it (Twiss, 1992).

Exploratory paradigm. According to this paradigm, future is the cause and effect result of past, thus a kind of determinism is hidden in it. The result of this 
viewpoint towards future is an obligatory and invariable future and based on history rules, present episode will lead to it. In this paradigm, man is just an external observer who can merely explore that obligatory future. It is based on prediction, and exploring the future is the only rational result of it. For instance, 'how much will Iran's population be in year 2026?' or 'how much will non-oil export of Iran be in the next 20 years?', which are mainly based upon analyzing previous procedures and maintaining them in oncoming years (Twiss, 1992).

Normative paradigm. This paradigm considers man's power in constructing the future, so a change is made in man's role as an external observer and we encounter the concept of shaping the future. According to this paradigm, man comes across a wide range of futures, including possible futures, probable futures and plausible futures, thus reaching each of them depends on the level and quality of man's will, i.e., man's favourable future. In contrast to exploratory paradigm, no hidden determinism exists in this paradigm and man is entirely free to choose his life pathway. As implied before, man deals with three main questions in this paradigm: 'which futures are possible to happen?', 'the occurrence of which futures is probable?', and 'which futures are preferable to occur?' (Khazaee, 2007; Vahidi-Motlagh, 2007).

Briefly speaking, the prediction approach in planning encountered a substantial challenge in last years of the second millennium, first of all because of considering future in a rigid way, and secondly due to insufficient accuracy (Nazemi, 2007).

Comparing these two paradigms indicates considerable differences between their planning methods for future. Planning process in exploratory paradigm begins from present time and directs toward future, i.e., it is outward bound and seeks to discover under different conditions which future will occur. So, the start point is often in present time. Conversely, normative paradigm makes use of an inward bound planning and its planning process begins from future. In other words, the start point here is in future and planning continues from future to present time using back-casting (Schwartz, 2008).

The two mentioned approaches contain furthermore the concepts of 'cause and effect' and 'long view'. Utilizing the principle of 'cause and effect', it is possible to explain what has taken place in past and predict what will occur in future. This principle is more similar to exploratory paradigm whose most significant tool is prediction. On the other hand, according to 'long view' principle, people's behaviour in future cannot be elucidated by reference to 'cause and effect' laws and in future, singularities may happen in procedures, which are called the wonders of science and technology. Hence, foresight and future study are its main planning tools. It should also be noticed that the 'cause and effect' approach is the traditional methodology towards planning, while 'long view' approach is the modern one used in planning.

In traditional approaches of planning, the programmer initially makes the required prediction by asking the question 'what will occur in far future?' and then 
considers these predictions as the basis for decision-making and policy-making and eventually proceeds (Foren, 2001). In other words, the programmer starts from current conditions and goes into future. Nevertheless, in modern viewpoint towards planning, the programmer at first goes into future and by monitoring present and past time determines the specific paths for development architecture from future to present time (Mobini-Dehkordi, 2008).

\section{PLANNING PROCESS}

In opinion of researchers, planning is a conscious process with the aim of solving existing problems and reaching a pathway for making changes in social system, which predicts a series of arranged executive operations considering the priorities (Masumi-Ashkevari, 2008). Most planning researchers agree with this definition of planning process, which has the following six key characteristics: being a process, being conscious, emphasis on problem solving, emphasis on priorities, objective determination and policy-making.

The reason why planning is defined as a process is to facilitate complete and better definition of problems, limitations and facilities, finding the optimum alternatives, rational decision-making based upon principles and feedback and revision capabilities. In traditional approach towards planning, this process consists of the following six main stages (figure 1).

In this approach, planning process has a linear flow and makes use of feedback subsequent to execution. The most significant part is determining the main goals, in which the future conditions are predicted and the main goals are determined by means of exploratory approach and primarily based on analyzing previous procedures. As was mentioned in preceding sections, in this viewpoint of planning, future alterations have specific connections and relationships with the transitions in past and present time, and no issue is considered about discontinuities and wild cards of science and technology when predicting the future world.

What are nowadays observed in urban and regional studies, especially in comprehensive plans and also national and regional macro plans, and their execution results confirm it, are the exploratory approach and its characteristics in predicting the future. Neglecting the capacities and capabilities of science and technology and their influence and application in solving present problems, i.e., resolving current challenges only by relying on potency of today's science and technology, would lead to inappropriate or false predictions for long periods in future. This will consequently cause numerous problems in execution time for managers and planners due to unprecedented changes. 


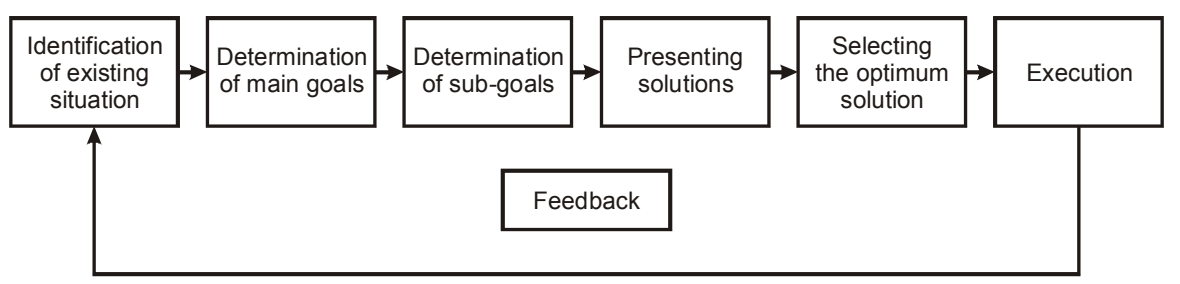

Fig. 1. Traditional planning process

Source: own elaboration based on Masumi-Ashkevari (2008)

\section{RE-ENGINEERING OF PLANNING PROCESS}

In the case of regarding planning as a move for reaching a preferable point and preparation for solving new world's problems, its process should as well be revised and mapped appropriate to new world's conditions. Reengineering is a methodology for rearranging the organization and management, and has attracted serious attention since the 1990s from planners owing to its novel style in investigating and modification of processes. Policy-making and -planning in traditional theories are accomplished based upon linear models (ERA, 2002), the linear planning based on prediction cannot, however, satisfy the necessities of planning in current and future world of changes. Due to scientific and technological advances, the transitions in present society are so accelerating and fast that reaching success in future would be impossible by merely relying on traditional planning, thus the modern approach of future study has been applied in scopes of management and planning. Instead of predicting the procedures and macro-procedures, the emphasis in this approach is on finding appropriate scopes in future world and considering the influence power of scientific and technological transitions in resolving challenges and problems of planning society. It emphasizes, other than evaluating the influence of continuing present procedures, the effects of initiating discrete procedures which possibly start in future.

\section{PRESENTING THE NEW PROCESS OF PLANNING}

The suggested process of planning, especially in urban and regional level, is based on normative approach. In this process, the basic step is to identify present state and then on the basis of this identification, the province key issues including its points of strength and weakness, capabilities and limitations are extracted. Subsequently, 
in the third step, overall and appropriate foresight at national and global level is done for key issues of the studied region. In the next stage vision and goals are defined. Defining the goals makes the development of pool of scenarios and choosing appropriate scenario possible for the programmer. This will provide a suitable background and framework for qualitative and quantitative goal setting, policy-making and finally executing. Our suggested planning process is fulfilled in the following ten stages (figure 2).

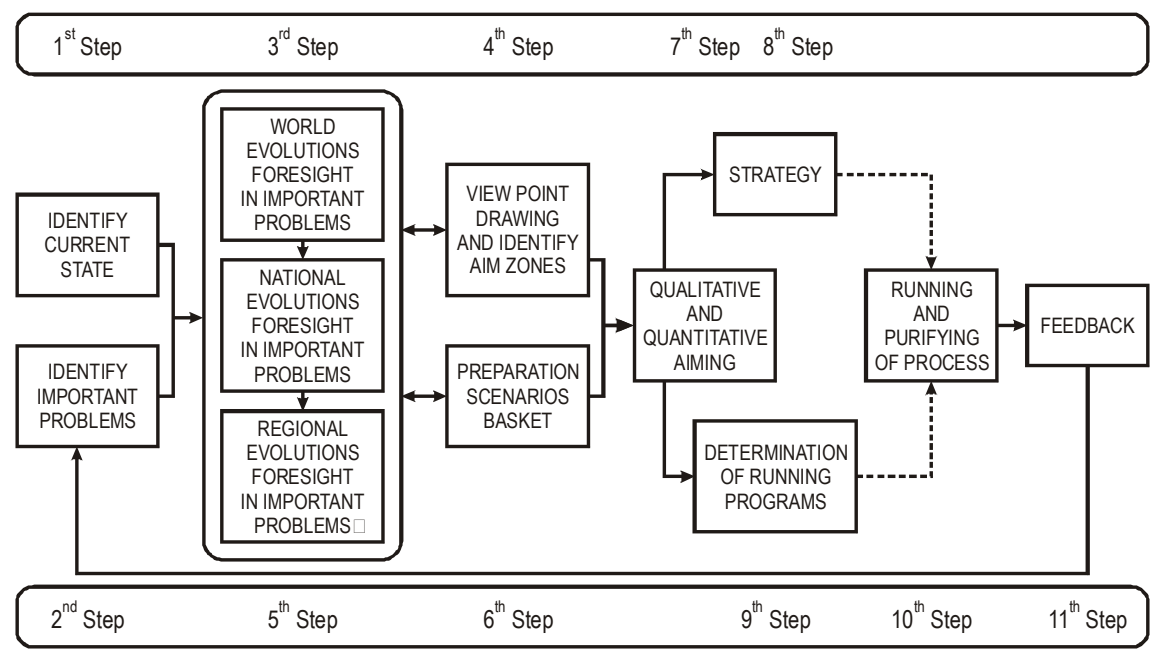

Fig. 2. New planning process from foresight view Source: own elaboration

Stage 1: identification of present state. In this stage, the regional state from past to present is studied. The data of limitations, capabilities and natural, economic, social and cultural resources are collected, categorized and then analyzed.

Stage 2: determining the key issues. On the base of outputs of 'identification of present state', regional key issues are extracted in different aspects and points of strength and weakness of the region in key issues are discussed. For instance, the key issues of a region for future twenty years may be as follows: providing drinking water, production efficacy in agriculture sector, providing clean energy for industries, concentration in metropolitans, emergence of a new generation of young elites, possibility of utilizing new energies (geothermal, solar etc.) and innovation in industrial technologies.

It should be mentioned that key issues are not only related to problems of a society or region. This issue can also include capabilities and probable and determined strengths of a region.

Stage 3: foresight. It is one of the most important steps of modern planning process which should be done essentially after identification of present state and 
determining regional key issues. In this step, foresight of global and national changes in the framework of key issues of studied region is discussed. For example, suppose there is the possibility of development of new strategies to use clean energies and use drinking water more effectively by use of new technologies. Being aware of these possibilities enables us to programme more effectively. So, this stage of the process is a bridge between regional key issues and determination of future goals and vision.

Stage 4: drawing the vision and determining goals. Besides defining programme horizons, in this stage the ideal goals for regional planning relative to the characteristics and strengths are determined and the aims in future horizon are also clearly defined. Outputs of stages 1-3 including identification of key issues and foresight are the raw inputs of drawing the vision and determining the aim. In other words, identification of current state as well as recognizing possible, plausible and probable future for provincial key issues are three key elements which make drawing the vision or the preferable future possible. Drawing the preferable future is the turning point of planning for past and future of the region, from this stage; planning is based on future formation.

To draw the vision, three levels of possible, plausible and probable future are evaluated (Twiss, 1992; Porter, 1991).

Possible futures include all possible states which can occur in future. These spectrums of futures consist of a set of images the individual has for his/her future which are mainly imaginary and result from mind imagination beyond the current human knowledge.

Plausible futures include the futures which are possible to occur in future, based on human current knowledge. Contrary to possible future which is in contrast with current human knowledge, this type of future is compatible with these concepts. Plausible futures are a subset of possible futures.

Probable futures point to the futures that will probably occur. These futures are a subset of plausible futures. In future scenario making, a combination of possible, plausible and probable futures draws the preferable future. To achieve that future, various scenarios are prepared, which makes the basket of contrast, relative, different and similar scenarios (Voros, 2003).

Stage 5: preparing basket of scenarios. To act in a world full of uncertainty, managers and planners should challenge their suppositions by questions such as 'what if this happens?' to have a clear vision of the future world. The goal of scenario making in planning is to help leaders and managers in changing their attitude toward their supposed reality and making their view closer to present or forming reality. The final result of scenario making is not drawing a correct map of the future, but its goals is to systematically modify and improve decision-making in fields related to goals of future. 


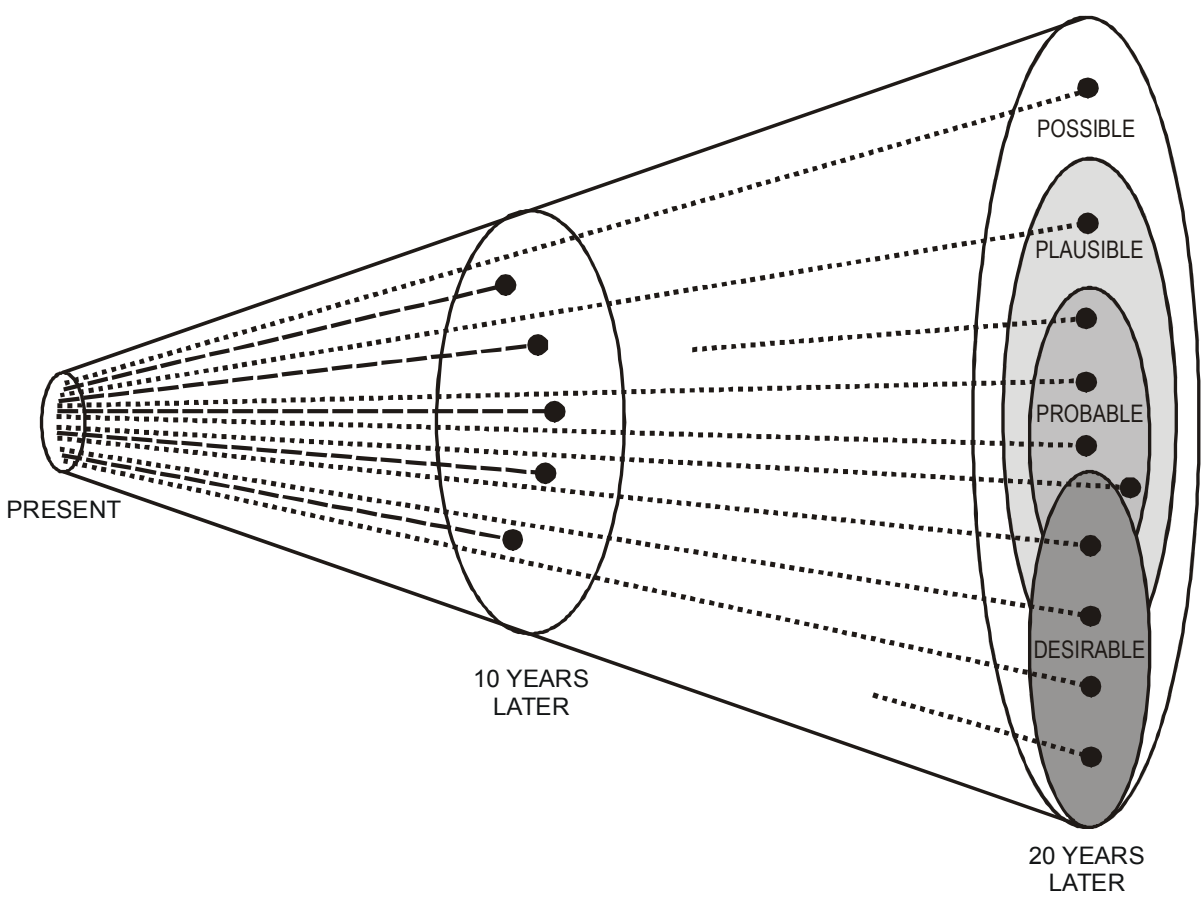

Fig. 3. Domain of futures in planning horizon Source: Lingren (2003)

Stage 6: selection of preferable scenario. Among the large number of prepared scenarios in the previous stage, preferable scenario which is designed appropriately for preferable future should be selected. Then, the effectiveness of science and technology changes on flexibility of selected scenario should be re-evaluated.

Stage 7: qualitative and quantitative goal making. The large scale strategies to give executive cover to the preferable scenario are defined in this stage. Beside the qualitative large scale goals, quantitative large scale goals are also defined in this step to determine the planning pathway precisely.

Stage 8: policy-making. In this stage, policies about the methods of putting the optimum scenario into action to achieve the preferable future are made.

Now, the ways of achieving qualitative and quantitative goals are defined in an absolutely executive manner.

Stage 9: preparing executive programmes. They are a set of economic and social projects which play a stimulating role for a region. Executive programmes are usually presented as a comprehensive package. For example, to develop a large factory of copper production, only the plan of developing the factory is not presented. But in the framework of a complex, various elements, such as sales market, 
transportation network, providing energy, accommodation of population and all issues related to the project are noted in a package and then would be listed according to their priority.

Stage 10: implementation and monitoring the process. This stage is in fact the objective presentation of attempts of the planning team to draw the preferable future and goal making for it. In this stage, other than the problems of execution, environmental changes are monitored and necessary changes are applied to different stages of planning.

Stage 11: feedback. This stage concludes work process evaluation and its positive/negative output, in fact. Positive or negative output can have important effect on process correction, impediments, problems or possibly deficiency of planning process.

\section{CONCLUSIONS}

In this current world which is full of changes, knowledgeable managers and planners, instead of waiting for the future in their working environment and then making decision while encountering it, have shifted their planning thoughts into future. Then, by supposing themselves in preferable future and having a retrospective approach from future to present, they label the development routes and subsequently define the policies to achieve the preferable future. Among the three stage of time: past, present and future, the most important one is future, as it draws the human life and motivates people to work. Past is not accessible and only its memories have remained and present is passing rapidly and cannot be influenced easily. Future is the only time we can plan for it to live in and with. Urban and regional planning, as a main branch of social planning, because of its close ties with organizations, people and executive organizations and rapid reflection of its performance, can offer great help in modification and improvement of planning processes and their re-engineering.

As it was mentioned, there are two basic approaches in planning: Explorative approach as an approach to discover the future and normative approach for future formation. It seems that the explorative approach has been widely used in planning for future in urban and regional planning. Considering the rapid changes in societies and the influence of science and technology on fast development and solving the problems of societies, many problems occur in fulfillment of such plans. As a result, these programmes undergo essential changes or in other words, a chaos has happened in these programmes.

So, it seems necessary to change our attitude from explorative approach to normative approach in future study. This article tries to criticize the traditional planning 
process which is based on the discovery of future. Moreover, here we present the idea of re-engineering the process of planning as well as desired modification of planning process based on future formation. These changes are all around the employment of foresight and its methods, rather than forecasting the future. Results of this article can be summarized as follows:

1. The philosophy of foresight has originated from the human and social sciences concepts, but human sciences suffer from a theoretical weakness in this field in a way that contrary to the developed countries, in Iran technical and engineering sciences are the founders and directors of foresight. Considering the nature of these sciences, it is not possible to comprehensively conduct foresight on the basis of national values by these sciences. So, it is essential to activate this dialogue in the field of social and human sciences to reinforce the philosophical basis of foresight on the foundation of national values.

2. Foresight in Iran is just an incomplete copy of European samples which is usually related to the technical and engineering sector.

3. Current problems of human societies have resulted from the imprecise identification of future. If today's society status is a result of forecasting in the past, so there were major problems in planning and our understanding of future.

4. The explorative paradigm in planning is trying to discover future in the world which is full of changes. This paradigm is only waiting for future and the necessity to change the approach in institutions responsible for planning to achieve success in future is obvious.

5. The effectiveness of normative approach in planning, which is trying to form the future, is in reduction and limitation of domain of uncertainties in future. However, employing foresight and evaluating the effect of all variables and key issues in future is necessary.

6. The process of traditional planning is linear and consists of six general stages. This process is centred around the forecasting of past trends in future without any emphasis on interrupted trends which may occur in future. So, it contains many shortcomings in foresight as it does not evaluate all characteristics of future.

7. Emergence of wild card interruptions in the era of information and communication, and also rapid globalization of changes in less than few years makes the re-engineering of the planning process to eliminate the forecasting approach and substitute it with foresight approach inevitable.

8. Determination of key issues and foresight of global and national changes is the most important stage which should be added to the planning process in the new approach.

9. Scenario making for future and making a basket of scenarios on the basis of effective variables on future society is another important stage in the new planning approach. It is necessary to be prepared to encounter any probable future in future world. 


\section{REFERENCES}

ERA (2002), The Potential of Regional Foresight, Final Report of the STRATA-ETAN Expert Group, European Research Area.

FALUDI, A. (1970), 'The Planning Environment and the Meaning of Planning', Regional Studies, 4 (1), pp. 1-9.

FOREN (2001), A Practical Guide to Regional Foresight, European Commision Research Directorate General, ESTRATA programme, December.

KHAZAEE, S. (2007), Future Researching: Concepts and Needs, http://www.ayandehpajoohi.com/ archive/00126.php.

LINGREN, M. (2003), Scenario Planning: The Link between Future and Strategy, New York: Palgrave Macmillan.

MASUMI-ASHKEVARI, H. (2008), Scientific Guidelines for Planning and Foresight, Tehran: Payam Press.

MOBINI-DEHKORDI, A. (2008), Mega Dimes as Strategic Need for Offices Futures, Tehran: International Energy Institute.

MYER, D. and KITSUSE, A. (2000), 'Construction the Future in Planning: A Survey of Theories and Tools', Journal of Planning Education and Research, 19 (3), pp. 221-231.

NAZEMI, A. (2007), Zone Foresight as Land Preparation, Tehran: Atinegar Idea Center.

NAZEMI-GHADIRI, A. (2006), Foresight from Concept to Running, Tehran: New Industries Center.

PORTER, A. L. (1991), Forecasting and Management of Technology, New York: Wiley.

SCHWARTZ, P. (2008), The Art of Future Vision, transl. A. Alizadeh, Defence Technology Science Foresight Centre.

TWISS (1992), Forecasting for Technologist and Engineers: A Practical Guide for Better Dictions, London: Peregrines.

VAHIDI-MOTLAGH, V. (2007), Foresight from Future to Day, Tehran: Atinegar Idea Center.

VOROS, J. (2003), ‘A Generic Foresight Process Framework’, Foresight, 5 (3), pp. 10-21. 